\title{
Reithosenfettsucht oder Dörrpflaumenanorexie?
}

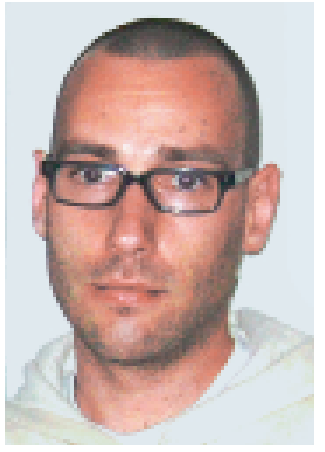

Daniel Berner,

lic. phil. I, BMI 21,5

ist Lektor beim Schweizerischen

Ärzteverlag EMH.
Zugegeben, über den ästhetischen Wert medizinischer Lexika lässt sich streiten, vor allem was die Bilder betrifft. Mag sein, dass der Mensch sich zu den schönen Dingen hingezogen fühlt, weil er mit ihnen die Vorstellung von Leben, Jugend und Glück verbindet und das vergängliche Schöne sucht, wo immer er es zu fassen vermag. Was uns aber von jeher mit schier magischer Kraft in seinen Bann schlägt, ist das Hässliche. Demgegenüber ist das Schöne vergleichsweise langweilig und im Prinzip auch ziemlich <unästhetisch», fade und geschmacklos, zumal sich «Ästhetik» vom griechischen «aisthesis» herleitet, womit die sinnliche Wahrnehmung (im Gegensatz zur geistigen Erkenntnis) gemeint ist. Das Schön-Geistige konsolidiert, beruhigt, und ehe wir's uns versehen, stehen wir als Gipsstatue da und lösen «interesseloses Wohlgefallen» aus. Das Hässliche hingegen provoziert eine körperliche Reaktion - Ekel -, es spricht in Affekten und zupft die Begleitakkorde dazu auf den Saiten unserer Nervenstränge. Es rüttelt uns aus dem süssen Schlummer der Anästhesie und bringt uns zur Besinnung (aber nicht zur Vernunft!), bis wir das Ästhetische mit jeder Faser unseres Leibes spüren.

Und nun liesse sich so richtig schön - oder hässlich - über den ästhetischen Wert medizinischer Lexika streiten ... Doch dazu vielleicht ein andermal; worauf ich eigentlich hinauswollte, ist, dass, wenn wir die ganzen Abscheulichkeiten einfach mal geflissentlich übersehen, so ein medizinisches Wörterbuch durchaus seine witzigen Seiten haben kann - was natürlich auch damit zu tun hat, dass das Hässliche interessant (von lat. «inter esse») - aber lassen wir das! - Eine dieser witzigen Seiten ist zum Beispiel die Seite 21 aus dem «Springer Lexikon Medizin», auf der die beiden gefürchteten «Adipositastypen» im Schattenriss zu sehen sind. Der eine heisst «android», weil er einem Apfel gleicht (oder umgekehrt), der oder besser die andere ist «gynoid» oder (weniger folgerichtig, dafür irgendwie poetisch) «birnenförmig». Aber abgesehen davon erinnert das Ganze eher an die Silhouette eines konspirativen Treffens zwischen Gerhard Schröder und Helmut Kohl.

Nun ist natürlich mein Interesse (Sie erinnern sich) geweckt - und tatsächlich steht auch das «Roche Lexikon Medizin» mit seiner sehr augenfälligen (evidenzbasierten) Illustration zur so- genannten «Reithosenfettsucht» (!) der Konkurrenz punkto Unterhaltung in nichts nach. Doch was suchen Schröder und Kohl im «Springer», und wo ist Angela Merkel?

Politik war ja schon immer eher misogyn. Daran konnte auch Kohls zunehmend deutlicher werdende Hang zum Androgynen bzw. Gynoiden nichts ändern. Zu Beginn seiner Amtszeit war er «ein Mann von Format». Allerdings weitete er sein Specktrum in der Folge derart aus, dass im Bundestag allmählich ein prekäres Un- bzw. Übergewicht entstand und er als einzige Frucht seiner Bemühungen nur den mässig schmeichelhaften Kosenamen «die Birne» erntete. Und es kam noch dicker: Als «die Birne» schliesslich überreif wurde und danach zur ungeniessbaren Abrissbirne petrifizierte, hatten die Deutschen genug von Kohl und überhaupt von Obst und Gemüse.

Aber als ein rotglänzender Apfel im Designeranzug weit vom Stamm fiel, wurde das Stimmvolk schwach, womit sich - wie schon in der Genesis - die SPD einmal mehr ums Politparadadies brachte, das seither übrigens auch nicht mehr so richtig grün werden will. Denn Schröder hatte dasselbe Problem wie Kohl, und selbst wenn er es - Brioni sei Dank - etwas besser zu kaschieren verstand, musste es allen bald schon klar sein: Gerhard war ein Apfelmännchen. Deshalb wollte man künftig seine Hoffnungen lieber auf ein Weibchen setzen, ein Weibchen mit engelsgleichem Namen - Angela - und pflaumiger Gestalt.

Die Merkel hat's aber auch schwer. Seit einem knappen Jahr blickt ganz Deutschland auf sie und auf ihr Äusseres - und fragt sich, welche Figur sie wohl machen und welche sie abgeben wird. Wird sie Gerhards Apfel widerstehen können und in Reithosen in Helmuts Fussstapfen treten? - Nachdem ihre beiden Vorgänger jedoch parallel zu ihrem Autoritätsverlust an Gewicht gewannen, könnte sie es sich als Frau aber auch etwas leichter machen und den genau entgegengesetzten Weg wählen: also Magerstatt Fettsucht. Und wer weiss, vielleicht werden wir bereits in einer der nächsten Auflagen von «Pschyrembel ${ }^{{ }}$\& Co. einen Eintrag samt Bild - zur sogenannten (gynandroiden) Dörrpflaumenanorexie (Anorexia pruniforma rugosa) finden ...

Daniel Berner* 